\title{
ASSESSMENT OF VISUAL EXAMINATION FOR WIRE ROPE SLINGS USING THE ATTRIBUTIVE MEASUREMENT SYSTEM ANALYSIS
}

\author{
Carmen SIMION \\ University Lucian Blaga from Sibiu, Faculty of Engineering, Romania \\ e-mail: carmen.simion@ulbsibiu.ro
}

\begin{abstract}
Wire ropes are used for a variety of day-to-day job operations. They have a finite service life and therefore requires consistent, thorough and documented examinations to identify component degradation before a failure. Conducting regular examinations is the most effective way to detect, monitor and respond to wire rope sling fatigue failures. Thorough routine examinations should be carried out by a capable and experienced person so the assessment of the visual examination for wire ropes is crucial to obtain the confidence in the inspection process.

The purpose of this paper is to determine if the persons using the sling in a day-to-day job have sufficient training and practical experience to perform visual examination of wire rope slings, using the method of attributive measurement system analysis. This method looks at how effective or capable a person is in accepting good products and sorting out bad products repeatedly and looks also at the probability of a bad product being missed and a good one rejected. The results were processed with MINITAB software.
\end{abstract}

KEYWORDS: wire rope slings, visual examination, discard criteria, attributive measurement system analysis

\section{Basics of wire rope sling}

Wire rope is a very complex machine having the primary function to move, which in turn is where it obtains its source of strength. It has three basic components: wires, strands and core (Fig. 2) [1, 2]:

- the wires are single and continuous lengths of metal materials including steel, iron, stainless steel, monel and bronze; they can be manufactured in a variety of grades that relate to the strength, resistance to wear, fatigue resistance, corrosion resistance and curve of the wire rope. The wires form the strands and together provide the rope's strength;

- the strands consist of two or more wires arranged and twisted in a specific arrangement; the individual strands are then laid in a helical pattern around the core of the rope. Strands made of larger diameter wires are more resistant to abrasion, while strands of smaller diameter wires are more flexible;

- the core, which forms a foundation for the strands, runs through the center of the rope and supports the strands and helps to maintain their relative position under loading and bending stresses.
Cores can be made from different materials including natural or synthetic fibers and steel to give the rope support and flexibility.



Fig. 1. Components of a wire rope [2]

Therefore, a wire rope is essentially numerous metal strands spiralled around the wire core. The construction of the wire rope is primarily specified by the number of strands and the number of wires in each strand. The arrangement of wires in the strand, 
type of lay and outer and core material depend on the rope's indispensable application for its usage. The main uses are running ropes, stationary (stay) ropes, track ropes and wire rope slings.

Wire rope sling (Fig. 2) is a preferred lifting device because it is one of the most reliable ways to secure a load to lifting equipment. Wire rope slings are light, strong, and durable and they can be used in a variety of ways for many different kinds of lifts. They are popular in the construction, automotive, oil and gas and general manufacturing industries where a variety of heavy loads and rugged conditions exist and also very popular in steel mills and forging facilities where the durability of the rope is really put to the test [2].

Traditional single-part wire rope slings are constructed from multiple steel wires that form individual strands laid in a helical pattern around a fiber or steel core. Different configurations of the material, wire and strand structure will provide different benefits for the specific lifting application, including: strength, flexibility, abrasion resistance, crushing resistance, fatigue resistance, corrosion resistance and rotation resistance [2].

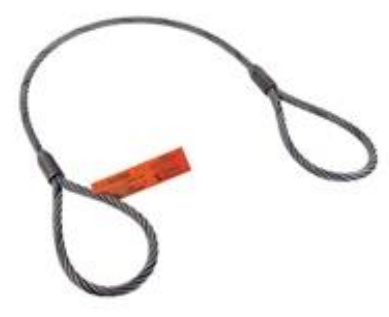

SINGLE-PART

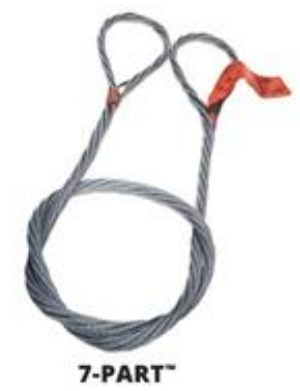

Fig. 2. Wire rope slings [2]

\subsection{Visual examination of wire rope slings}

Better performance of wire rope slings is achieved if and only if they are healthy. This is assured when maintenance and inspection are carried out at regular interval of time by a capable person.

Wire rope sling is a consumed item and therefore requires consistent, thorough and documented inspections to identify component degradation before a failure. Detailed inspection requirements for wire rope slings are described in the international standards such as ISO 8792, federal regulations such as OSHA 1910.184 and applicable industry standards such as ASME B30.9.

There are two major non-destructive inspection methods: visual examination (the most effective) that is useful for detecting external deterioration and electromagnetic inspection for the detection of internal damages.
To ensure that all wire rope slings are properly inspected, it is important to know how frequently inspections should be performed, who should perform the inspections and what criteria should be examined to pass an inspection.

During service, wire rope slings are subjected to conditions which affect their safe working characteristics. It is necessary therefore to ensure that the sling is safe for continued use. The sling shall be inspected for damage or deterioration before each period of use and therefore shall be checked for obvious defects at suitable intervals during service. In addition, thorough routine examinations (visual examination) shall be carried out, at intervals not exceeding six months and this interval shall be less where deemed necessary or where required by statutory requirements, by a competent person. Where necessary, the thorough examinations shall be supplemented by other means such as non-destructive testing in order to detect damage or deterioration which might affect the firmness for use of the wire rope sling [3].

A specific procedure for wire rope sling inspection is the best safeguard against injury, death and property damage. To detect possible damage, it is necessary to perform a visual inspection throughout their entire length.

All wire rope slings should be inspected at regular intervals and it is important to employ a threestage level of inspection to ensure that slings are inspected with appropriate frequency $[2,4,5]$ :

- Initial inspection (prior to initial use) upon receiving from the manufacturer. Double-check the sling tag to make sure it's what you ordered and that the rated capacity meets all of your project specifications and lifting requirements.

- Frequent (daily at the beginning of each work period or prior to use): a designate competent person must also determine that the wire rope sling is proper for the intended use, hitch, load and environment. Any condition that may result in a hazard shall cause the sling to be removed from service.

The designated person is selected or assigned by the employer or employer's representative as being competent to perform specific duties.

All running ropes and slings in service should be visually inspected once each working day.

- Periodic inspection, performed by either a professional service provider or by a qualified person.

Qualified person is a person, who by possession of a recognized degree or certificate of professional standing in an applicable field, or who, by extensive knowledge, training and experience, has successfully demonstrated the ability to solve or resolve problems relating to the subject matter and work.

The interval of periodic inspection is based upon: the frequency of use, severity of the service 
conditions, the nature of the work being performed and experience gained during the inspection of slings.

At least one periodic inspection is required annually, but ASME provides these additional periodic inspection guidelines based on the service of the wire rope sling: normal service - yearly, severe service - monthly to quarterly and special service - as recommended by a qualified person.

The visual examination should be carried out by appropriately qualified, capable, experienced person using the wire rope in a day-to-day job who has learned through special training or practical experience what to look for and who knows how to judge the importance of any abnormal conditions they may discover. It is the responsibility of the person making the inspection to follow the proper inspection criteria for each application [4].

\subsection{Basic inspection criteria}

While inspecting (examination) a wire rope sling there are certain important considerations that need to be kept in mind. Once such consideration is of course the frequency of it use, but some other important aspects include: application of the wire rope sling, operational conditions like weather etc., manufacturer recommendations and statutory requirements and analysis of wire rope sling history of its previous used for the same application.

An inspection (examination) consists of observation of all wire ropes and end connections which can reasonably be expected to be in use during daily operations.

ISO, OSHA and ASME specific that wire rope slings shall be removed from service if any of the following mainly discard criteria are visible $[3,6,7]$ :

- missing or illegible sling identification (tag);

- broken wires/localized faults (LFs);

- corrosion of the rope or end attachments;

- distortion/deformation: kinking, crushing, bird caging (basket deformation), doglegs or any other damage resulting in distortion of the structure;

- mechanical damage at end attachments;

- heat damage (including electric arcing) which is evident by wire discoloration, burn marks, weld splatter, etc.;

- decrease (reduction) in rope diameter/loss of metallic area (LMA);

- other conditions, including visible damage that cause doubt as to be continued use of the wire rope sling.

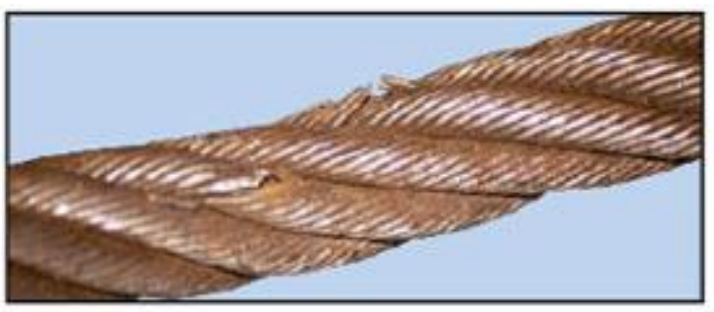

Broken wires

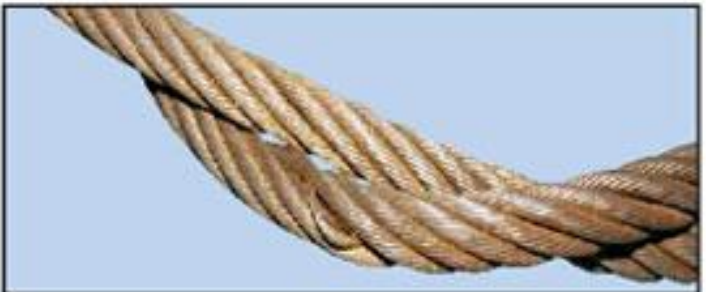

Doglegs

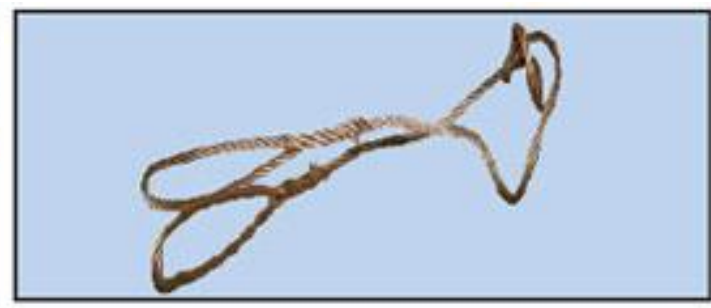

Kinked wires

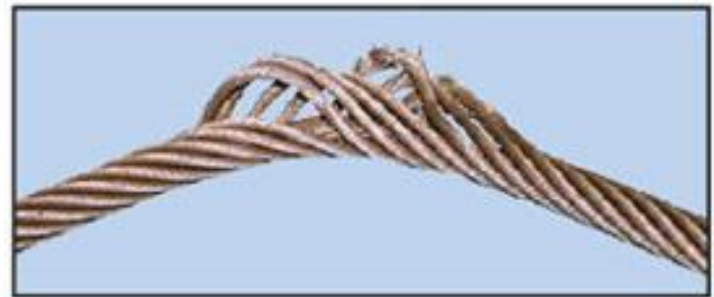

Bird caging

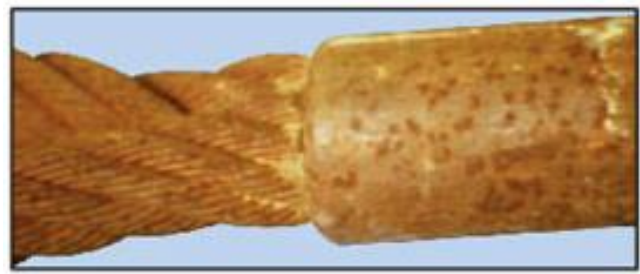

Corrosion

Fig. 3. Basic inspection criteria [5] 


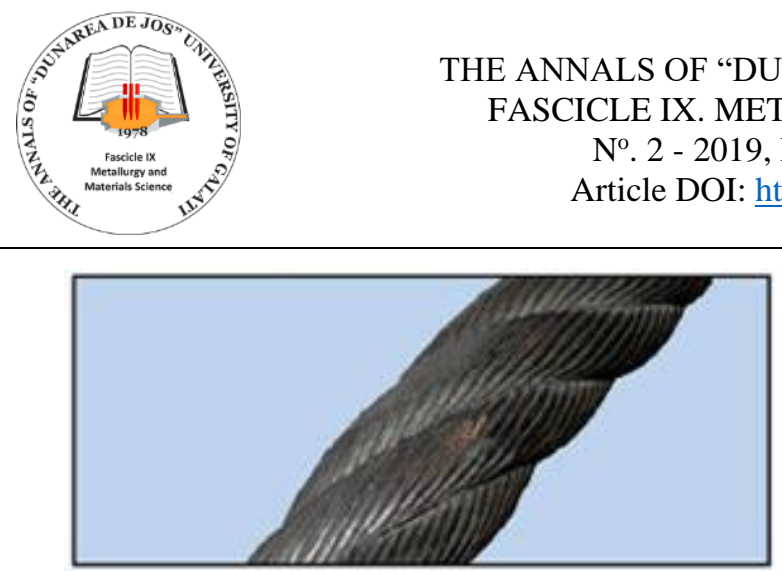

Abraded/worn wire

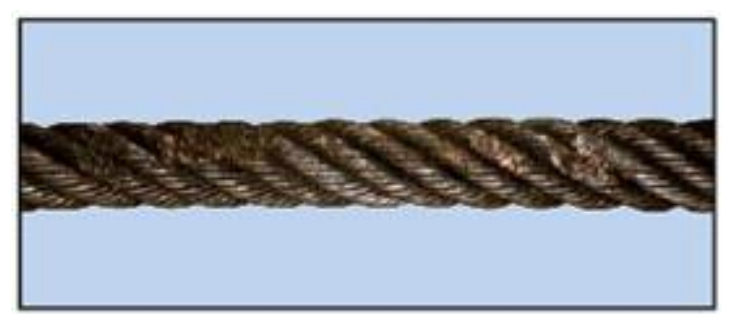

Heat damage



Fig. 3. Basic inspection criteria - continued [5]

\section{About attributive measurement system analysis}

A measurement system is a collection of operations, procedures, gages and other equipment, software and personnel used to assign a number or a qualificative to the characteristic being measured or categorized [8]. Measurement system can be divided into two categories: variable (for continuous data) and attribute measurement system (for discrete data).

Most problematic measurement system issues come from measuring discrete data, which are usually the result of human judgment when categorizing products "good" or "bad" as a result of the visual inspection. This is because it is very difficult for all inspectors/appraisers to apply the same operational definition of what is "good" and what is "bad". However, such measurement systems are seen everywhere so it is important to quantify how well they are working [9].

The attributive measurement system analysis is a set of trials conducted to assess the inspector ability to categorize products. The methodology involves multiple inspectors (two or more) that categorize, independently and in a random order, multiple products (usually between 20 and 30) multiple number of times (two or more trials). Measures are calculated based on how often the inspectors correctly characterize each product (agreement with the standard) and how frequently they agree with themselves and each other.

The methodology uses two primary methods of assessing the agreement of the attribute with the standard: the percentage or extent to which the inspectors agree with the standard and Kappa statistics (the percentage or extent to which adjustment is made between the agreement between the appraisals and the standard, after chance agreement has been removed) [8-10]:

- agreement within inspector: the percentage or extent to which each inspector agrees with himself or herself on all trials when each inspector conducts more than one trial;

- agreement between inspectors: the percentage or extent to which all inspectors agree with each other on all trials when more than one inspector makes one or more trials;

- agreement of each inspector versus standard: the percentage or extent to which each inspector agrees with himself or herself as well as with the standard when a known standard is specified;

- agreement of all inspectors versus standard: the percentage or extent to which inspectors agree with each other on all trials as well as with the standard when a known standard is specified;

- kappa statistic indicating the degree of agreement of the assessments made by multiple inspectors when evaluating the same products; Fleiss's kappa - statistic used for assessing the reliability of agreement when inspectors are selected at random from a group of available inspectors; Cohen's kappa - statistic used for assessing the reliability of agreement when the inspectors are specifically chosen and are fixed.

The key in all measurement systems is having a clear assessment method and clear criteria for what to accept and what to reject. The hypothesis test analysis method, used in this analysis, consists mainly of qualificative/classification counting and division and the results are evaluated using acceptability criteria from AIAG MSA reference manual presented in 
Table 1 [8]. For any marginally acceptable or unacceptable measurement system, corrective action is required and when corrective action is completed, the attribute MSA must be redone.

Table 1. Decision criteria [8]

\begin{tabular}{|c|c|c|c|}
\hline Measures & Excellent & Acceptable & $\begin{array}{c}\text { Not } \\
\text { acceptable }\end{array}$ \\
\hline $\begin{array}{c}\text { Within } \\
\text { Appraisers }\end{array}$ & $>90 \%$ & $80 \%-90 \%$ & $<80 \%$ \\
\hline $\begin{array}{c}\text { Appraiser vs. } \\
\text { Standard }\end{array}$ & $>90 \%$ & $80 \%-90 \%$ & $<80 \%$ \\
\hline $\begin{array}{c}\text { Disagreement } \\
\text { G/NG }\end{array}$ & $<2 \%$ & $2 \%-5 \%$ & $>5 \%$ \\
\hline $\begin{array}{c}\text { Disagreement } \\
\text { NG/G }\end{array}$ & $<5 \%$ & $5 \%-10 \%$ & $>10 \%$ \\
\hline $\begin{array}{c}\text { Between } \\
\text { Appraisers }\end{array}$ & $>90 \%$ & $80 \%-90 \%$ & $<80 \%$ \\
\hline $\begin{array}{c}\text { Appraisers vs } \\
\text { Standard }\end{array}$ & $>90 \%$ & $80 \%-90 \%$ & $<80 \%$ \\
\hline
\end{tabular}

A general rule of thumb is that values of kappa greater than 0.75 indicate good to excellent agreement (with a maximum kappa $=1$ ); values between 0.40 and 0.75 indicate marginal agreement and values less than 0.40 indicate poor agreement [8].

\section{Case study}

Because it is important that all inspections must be done by appropriately qualified and capable personnel, the purpose of the paper is to determine if the persons using the wire rope slings in a day-to-day job have sufficient training and practical experience to perform their visual examination.

In order to assess the inspection process, the attributive MSA method was used. This looks at how effective or capable a person (appraiser) is in accepting good products and sorting out bad products repeatedly and looks also at the probability of a bad product being missed and a good one rejected.

The results were processed using MINITAB software with its module called Attribute Agreement Analysis [11].

Analysing results of the research, presented in Figure 4 and Tables 2 to 6 , the conclusions are:

- Within Appraisers (Individual Repeatability of inspectors) is above 90\%, so excellent (Fig. 5 - left side and Table 2): this means that inspectors are consistently with themselves; also, Fleiss's values of kappa statistic indicate very good (for appraiser 3 ) to excellent agreement (for appraiser 1 and 2);

- Each Appraiser vs. Standard (Individual Effectiveness of inspectors) is also above $90 \%$, so excellent (Fig. 5 - right and Table 3): this means that inspectors are in agreement with the true status (standard) of the wire rope sling; also, Fleiss's values of kappa statistics indicate very good (for appraiser 2 and 3) to excellent agreement (for appraiser 1);

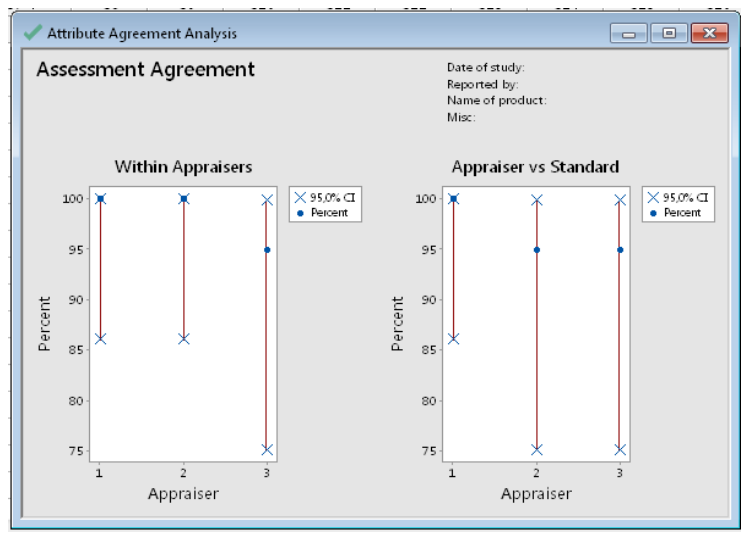

Fig. 4. Minitab graphs

Table 2. Within appraisers' results

\begin{tabular}{|c|c|c|c|}
\hline Appraiser & \# Inspected & \# Matched & Percent \\
\hline 1 & 20 & 20 & 100.00 \\
\hline 2 & 20 & 20 & 100.00 \\
\hline 3 & 20 & 19 & 95.00 \\
\hline
\end{tabular}

\# Matched: Inspector agrees with him/herself across trials

\begin{tabular}{|c|c|c|}
\hline \multicolumn{3}{|c|}{ Fleiss' Kappa Statistics } \\
\hline Appraiser & Response & Kappa \\
\hline 1 & G & 1.00000 \\
\hline & NG & 1.00000 \\
\hline 2 & G & 1.00000 \\
\hline & NG & 1.00000 \\
\hline 3 & G & 0.85663 \\
\hline & NG & 0.85663 \\
\hline
\end{tabular}

Table 3. Each appraiser vs. standard results

\begin{tabular}{|c|c|c|c|}
\hline Appraiser & \# Inspected & \# Matched & Percent \\
\hline 1 & 20 & 20 & 100,00 \\
\hline 2 & 20 & 19 & 95,00 \\
\hline 3 & 20 & 19 & 95,00 \\
\hline
\end{tabular}

\# Matched: Inspector's assessment across trials agrees with the hnown standard

\begin{tabular}{|c|c|c|}
\hline \multicolumn{3}{|c|}{ Fleiss' Kappa Statistics } \\
\hline Appraiser & Response & Kappa \\
\hline 1 & G & 1.00000 \\
\hline & NG & 1.00000 \\
\hline 2 & G & 0.85663 \\
\hline & NG & 0.85663 \\
\hline 3 & G & 0.92832 \\
\hline & NG & 0.92832 \\
\hline
\end{tabular}

- Assessment Disagreement (Table 4) results show that inspector 2 classified a good wire rope 
sling as a bad one on 1 occasion and inspector 3 was inconsistent in his judgments on 1 occasion;

- Between Appraisers (Reproducibility of Measurement System), shows that all three inspectors agreed with each other on both assessments to $90 \%$ (on 18 out of 20 inspected wire rope slings), so acceptable; Fleiss's values of kappa statistic indicate good agreement, too (Table 5).

Table 4. Assessment disagreement results

\begin{tabular}{|c|c|c|c|c|c|c|}
\hline Person & \# NG/G & $\%$ & \# G/NG & $\%$ & \# Mixed & $\%$ \\
\hline 1 & 0 & 0 & 0 & 0 & 0 & 0 \\
\hline 2 & 0 & 0 & 1 & 20 & 0 & 0 \\
\hline 3 & 0 & 0 & 0 & 0 & 1 & 5 \\
\hline
\end{tabular}

\# NG/G: Assessment across trials $=\mathrm{NG} /$ standard $=\mathrm{G}$ \# G/NG: Assessment across trials $=\mathrm{G} /$ standard $=\mathrm{NG}$ \# Mixed: Assessment across trials are not identical

Table 5. Between appraisers' results

\begin{tabular}{|c|c|c|}
\hline \# Inspected & \# Matched & Percent \\
\hline 20 & 18 & 90.00 \\
\hline
\end{tabular}

\# Matched: All inspectors' assessments agree with each other

\begin{tabular}{|c|c|c|}
\hline \multicolumn{3}{|c|}{ Fleiss' Kappa Statistics } \\
\hline Response & Kappa & SE Kappa \\
\hline G & 0.875747 & 0.0577350 \\
\hline NG & 0.875747 & 0.0577350 \\
\hline
\end{tabular}

Table 6. All appraisers versus standard results

\begin{tabular}{|c|c|c|}
\hline \# Inspected & \# Matched & Percent \\
\hline 20 & 18 & 90.00 \\
\hline
\end{tabular}

\# Matched: All inspectors' assessments agree with the known standard

\begin{tabular}{|c|c|c|}
\hline \multicolumn{3}{|c|}{ Fleiss' Kappa Statistics } \\
\hline Response & Kappa & SE Kappa \\
\hline G & 0.928315 & 0.0912871 \\
\hline NG & 0.928315 & 0.0912871 \\
\hline
\end{tabular}

- All Appraisers versus Standard (overall Effectiveness of the Measurement System) tells that for 18 out of 20 wire rope slings inspected all three inspectors agreed with the true status, which represents $90 \%$, so acceptable;

Fleiss's values of kappa statistics indicate also a very good agreement (Table 6).
In conclusion, the visual examination of wire rope slings is carried out by appropriately qualified, capable and experienced personnel and conducting regular examinations is the most effective way to detect, monitor and respond to wire rope sling fatigue failures.

\section{Conclusions}

Human measurement systems are often used to perform visual inspection, so their assessment is important to see where the problems are and eliminate them. The attribute MSA study is just one of many such tools that may be used to verify the validity of the data collected through a measurement system.

Because most processes require at least some form of subjective judgment, visual inspection must be carried out by a trained person, in which any product defect is detected by the aid of a naked eye.

Good practice requires that all wire rope slings should be subject to a frequent inspection to ensure that they are proper for the intended use.

The paper demonstrated an effective mean by which to evaluate inspection personnel capability to assess the quality of the wire rope slings through visual examination, using attributive measurement analysis technique.

\section{References}

[1]. ***, https://www.osha.gov/dts/shib/shib011917.html.

[2]. ***, https://www.mazzellacompanies.com/Resources/Blog/.

[3]. ***, Wire rope slings - Safety criteria and inspection procedures for use, ISO 8792, 1986.

[4]. ***, https://www.spanco.com/wire-rope-sling-inspection/.

[5]. ***, https://www.lift-it.com/info-wire-rope-considerations,

https://www.rentlgh.com/blog/how-to-inspect-wire-rope-slings/.

[6]. ***, ASME B30.9, Slings, 2018.

[7]. ***, OSHA 1910.184, Slings.

[8]. ***, Automotive Industry Action Group (AIAG),

Measurement Systems Analysis, $4^{\text {th }}$ edition, Detroit-Michigan, 2010 .

[9]. ***, http://www.isixsigma.com/tools-templates/measurementsystems-analysis-msa-gage-rr/making-sense-attribute-gage-rrcalculations/.

[10]. Durivage M. A., Practical attribute and variable measurement system analysis (MSA): a guide for conducting gage $R \& R$ studies and test validations, Quality Press, ISNB 978-087389-915-4, 2016.

[11]. ***, Minitab 17 Statistical Software, State College, PA: Minitab, Inc., 2010 